\title{
Comments on the special issue
}

\author{
Marcus Felson • Ronald V. Clarke
}

Published online: 12 June 2012

(C) Springer Science+Business Media, LLC 2012

\section{Introduction}

The theoretical case for the situational prevention of organized crime (Bouloukos et al. 2003; Cornish and Clarke 2001; Felson 2006) was significantly advanced by Dutch researchers, who were the first to undertake empirical studies of the situational prevention of organized crimes (Van de Bunt and Van der Schoot 2003; Van der Schoot 2006). In the first of these studies, published by the Research and Documentation Centre (WODC) of the Dutch Ministry of Justice, research teams from several European countries were enlisted to examine police records of prosecuted cases of organized crime with the goal of identifying the facilitating circumstances for each case and related opportunity-reducing measures. More recently, three of the 11 chapters in Situational Prevention of Organized Crimes (Bullock et al. 2010) were written by Dutch authors. Now, the seven new studies of situational prevention of organized crime included in this two-volume issue of Trends in Organized Crime were all produced by researchers in the Dutch National Crime Squad. Not only are these researchers to be congratulated, but so also are their bosses who recognized the value of sharing their work with the wider academic community.

\section{Avoiding distractions}

One of the major strengths of this volume is the authors avoided the six major distractions that so often impair progress in studying organized crime:

1. The Why Distraction: Engaging in endless discussion about "why they do this," when most organized crime is simply a way to make money.

M. Felson $(\square)$

Texas State University, 10109 Wild Dunes Drive, Austin, TX 78747, USA

e-mail:mf38@txstate.edu

R. V. Clarke

School of Criminal Justice, Rutgers University, Newark, NJ 07102, USA

e-mail: RVGClarke@aol.com 
2. The Kingpin Distraction: Spending too much time figuring out who is in charge or how a hierarchy works, rather than considering whether the crime process is largely decentralized.

3. The Personal Distraction: Paying greater attention to the individuals who cooperate in crime as whole persons rather than their roles and activities in the crime itself.

4. The Relationship Distraction: Worrying about the interpersonal and other relationships among offenders, rather than focusing on their illegal activities per se.

5. The Size Distraction: Using the widest reach of related illegal activities, however indirect and remote, instead of focusing on more ordinary and proximate behaviors that better describe what really happens.

6. The Homogeneity Distraction: Assuming that all stages of a crime process are equally organized and similarly cooperative, when in fact some stages involve more and some stages require less cooperation.

We realize that many of the distractions above are justified by other purposes. For example, paying attention to individuals makes good sense for prosecution, but not for prevention or even control.

We have mostly been observing these efforts from the sidelines, but on various occasions we have jointly or independently proposed principles for the situational prevention of organized crimes. Our approach has emphasized the criminal acts, not the criminals. That not only produces far better analysis, but also provides many more opportunities for prevention at low cost and within a shorter time frame. It is best not to presume a clear and consistent hierarchy of responsibility at all stages of the crimes. It is instead a good idea to ask exactly how cooperation and coordination assist the crime process at each stage, allowing that at some stages it may not be necessary at all. Intelligent design of organized criminal behavior is often an illusion and it is best to begin by assuming that organization and design are weak and loose. The various stages of an organized crime can include activities that are organized strongly, weakly, and hardly organized at all. Organized crime activities involve several persons, a sequence of several steps, and covering more than one transaction, often spanning more than a day. The process involves repetition of the same illicit activities, as well as the same supportive legal activities, and many of the same people again and again. Yet it need not require exactly the same people or exactly the same sequence. Often the ongoing structure is determined by the same locations, designs and activities but with fluctuations in the cast of participants at any given time. Hence place, time, and sequence may prove to the central structural components, while the specific persons involved are at least partly incidental to that structure. Indeed, the main reason for repetitive criminal cooperation among some of the same people may prove to be their need for trust and security. We might view each offender as having some experience and rules to decide whom to trust for joint illicit action.

The most fruitful way to navigate this complexity and to identify a role for situational prevention is to focus on the nature of the crimes committed. One or two core crime types most likely drive the activities of a particular group, and other criminal acts are subsidiary or supportive. Thus bribing officials may be a supportive activity, with the core activity drug retailing. It is important to figure out exactly how the core crimes are committed, when, where, how and with whom. Similarly 
important is to figure out a coherent step-by-step analysis of the modus operandi, the sequence through which the illegal actions proceed. It is also important to analyze the opportunity structure for these illegal acts in the context of legal activities upon which they feed or depend. Furthermore, one should try to identify the promising pinchpoints for intervention in the modus operandi or opportunity structure, thus undermining the crime sequence and illicit outcomes. The last point is to value prevention rather than arrest, since the latter cannot always disrupt the opportunity structure or prevent the replacement of individuals removed from the scene.

\section{Why these papers are important}

The papers in this volume generally avoid the mistakes we identify above and they follow the sequence of actions needed to analyze the crimes committed, but our purpose here is less to document these facts than to discuss why these papers constitute an important contribution to the field.

As theorists on organized crimes, we have constantly come across a fundamental problem - the lack of usable details. On one topic after another we have struggled with an excess of generalities that are too broad, or with an excess of details that cannot be usefully assimilated into useful categories. Thus it has taken many years of effort to learn that there are numerous categories of motor vehicle theft, to work out how each one is done, and which specific situational prevention techniques apply to each. We have learned that different models of car are stolen to be sent abroad, to be stripped for parts, for transport home, for joyriding, to carry out another felony, for just one part or for the contents alone. It took some time to disaggregate the different places from which vehicles are stolen, their relative risks, and what to do about it. However, once this information was compiled, our understanding of motor vehicle theft and how to address it has greatly increased.

Organized crimes consist of many hundreds of crime types, involving theft from individuals, groups, and formal organizations, involving small crimes at high scale, high crimes at small scale, and even small crimes such as intimidation and bribery at small scale repetitively over time. Indeed, the main common denominator for the field may not be the word "organized" but rather the sense of repetition and prolongation. Crime cooperation can occur at any given moment with several persons involved, but only if that cooperation is prolonged and many of the same people continue to cooperate does it gain our attention as being somehow organized.

Yet organization levels are extremely diverse, and can be very primitive and rudimentary. Thus the same bar or hangout may be the main common feature for prolonging a crime activity and giving us a sense of something larger than a few isolated incidents. There is a strong temptation not only to exaggerate the degree of coordination, but also to understate the vast variety in how offenders act together.

The papers in this volume make two important contributions that fill out this view of organized crimes. First, they amply illustrate their complexity and variety; indeed if there were anything depressing about the papers, it would be the glimpse they provide of the sheer volume of work needed if organized crimes are to be understood and prevented. Indeed, it is now more apparent than ever why criminologists are mostly lumpers not splitters; adopting a crime-specific focus and becoming a splitter, 
makes the criminological endeavor far more difficult and complicated. It becomes much harder to speak in abstractions and pontificate about the causes of crime - but once you learn how to study crime's specificity criminology becomes in our experience far more interesting.

The second contribution that these chapters make is the patient description of particular forms of organized crimes and the insights that result. In their chapter "Willing offenders outwitting capable guardians," Huisman and Jansen offer us an example at one extreme. They describe motorcycle gang members as well as another very insular group of people who reside in trailer communities in the Netherlands. This allows them to devise various criminal activities while avoiding scrutiny by police or other outsiders. Their social and residential insularity provides their protection. The particular crimes are often not very organized and do not necessarily involve many or even the same participants. The group participation is not in the crimes themselves but rather in the cover-up of what may otherwise be rather ordinary criminal transactions. This is a form of "organized insulation" for what are often rudimentary crimes, including transporting stolen contraband or providing illegal services. The crime tasks are not the challenge. Rather, cooperation is required to suppress the information and protect the offenders from outside interference. This insulation is accomplished partly by a common membership in a deviant group, within common incentives to protect one another from detection. It is also accomplished by a serious threat of violent retaliation against anybody who cooperates with law enforcement or against other offenders who interfere.

Huisman and Jansen also apply the concept of "convergence setting," showing that trailer parks and motorcycle groups converge to trade information on illegal opportunities. Even though their particular illegal acts are often carried out in small groups, cooffenders find one another in the context of their residence and group membership. Again, the organization applies not to the particular criminal acts so much as to the places where co-offenders find one another under protection from outside interference.

These findings from the Netherlands have implications well beyond the country's borders: they tell us that in some cases the main reason for crime organization is not the crime tasks themselves - which could be rather ordinary - but rather to give extraordinary protection to otherwise ordinary crime. To be sure, some less than ordinary crime may require such protection and thus be overrepresented among the criminal acts of such organizations. Perhaps we need to refine our notion of routine and ordinary criminal actions. Some crimes are ordinary in any one event but are not easily repeated over a prolonged period without detection and punishment. Thus ordinary crimes can have an extraordinary requirement. For example, prolonged sale of contraband in the same locations requires protection of a niche from police and other offenders. Even though any given sale of prostitution or drugs may be rudimentary and mundane, protection of the prolonged sale in the same location by the same people poses an organizational problem handled by a code of silence and a capacity for intimidation and corruption when necessary. Indeed, one of the hallmarks of some organized crime activities is to provide extraordinary responses when needed to protect ordinary and ongoing illicit repetitions of activities that, one by one, require precious little coordination or cooperation.

This impels us to ask ourselves whether the term, "organized crimes" really begs the question. We may presume that some aspect of crime must be organized in a 
continued way, but such organization need not apply to all or even most of the ongoing crime process. Reuter (1983) made us aware of this point in describing certain illegal gambling enterprises in the United States, which depended on an illicit "banker" to provide money when losses were great in a given week, but operated largely autonomously in their normal routines. Even if the ongoing crime depends on one relatively organized aspect, this does not mean the other features of the illegal process cannot remain rather rudimentary. The question we should always ask of "organized crime" is what part is organized and what part not.

In their chapter, "Cybercrime and virtual offender convergence settings," Soudijn and Zegers show us that illegal credit card activities can operate in a highly dispersed fashion with minimal cooperation at most stages. However, the offenders benefit from a common online forum to provide them with crucial information, serving as a virtual convergence setting. That means that offenders cooperate using the forum to trade illicit information while seeking to protect their anonymity. Yet their actual offenses may be simple and local, requiring minimal organization on the spot. Soudijn and Zegers further describe how money laundering occurs through wiring of cash, with relatively simple bank deposits coordinated by the virtual information sharing. Only one part of the crime process involves illicit coordination on a rather larger scale. In this case, the crime process generates particular vulnerabilities for offenders, whose activities can be thwarted at their weak point.

It is interesting to contrast these two chapters in terms of offender vulnerability. In the case of bikers and trailer parks, the ongoing cooperation among offenders serves to reduce their vulnerability to law enforcement and to other offenders interfering with them. The opposite appears to occur with virtual offender convergence settings, where offenders are relatively vulnerable to interference by law enforcement and to manipulation or attack by other offenders. Vetting offenders and guarantying their trustworthiness is present in all cases, but more problematical in the virtual world. That leads us to ask another question in future organizational analysis: Does the higher level of organization and cooperation expose offenders to greater vulnerability, or does it serve to reduce that vulnerability? We also need to guard against assuming that offenders fear law enforcement the most. In fact their greatest fear may be predation by other offenders, organized or not, and hence their defensive concerns must be understood for proper analysis.

A different set of questions emerges from the chapter by Franca van der Laan, "They simply continue their business: Organizing crime from prison." The specific significance of this chapter is its routine activity analysis of how crime organizers continue their illegal directions while incarcerated. The analysis considers how offenders use prison jobs, visitors, prison personnel, family members, and codetainees to continue illicit enterprises. The policy implications are to advise prison officials how to interfere with this process. This paper leads us to wonder whether criminal enterprise is rather simpler than meets the eye, at least in organizational terms, if it can be coordinated from behind bars.

An essential task for situational analysis of organized crime is to divide the crime tasks into layers of activity, with a clear understanding of their sequencing. In the chapter, "Removing excuses in money laundering," Soudijn distinguishes several stages in the crime. Starting with three phases - placement, layering, and integration the process is analyzed in some detail. Although Soudijn criticizes these traditional 
three steps, the important point is that he is very attuned to modus operandi and especially sequencing. By making these explicit, one not only arrives at a much better intellectual understanding of how crime is organized, but one is much better able to figure out what to do about it. Not only does the money laundering chapter illustrate the importance of detailed sequencing, but it also explains how financial facilitators assist illicit monetary transactions. Persons with otherwise legitimate roles must knowingly, half-knowingly, or unknowingly change cash into large bills, move the cash about, or leave it alone if concealed. In the 22 case studies, all financial facilitators were knowingly and willingly involved, but the possibility remains open that money laundering can also be facilitated more innocently. The author distinguishes facilitators whose activities are organized around cash from those who contributed to documentation making money laundering seem legitimate. Again, we see that the illegal tasks vary in the amount of cooperation and coordination they require, and the type of skill and knowledge needed.

In his chapter on the situational prevention of terrorism, Weenink disaggregates several steps in terrorism related plots in the Netherlands. These steps are then applied to situational prevention of terrorism. Included are preventing terrorists from entering the country, interfering with fund raising and fund transfers. They also ask at what point the police should take action. The earliest possible stage varies by circumstance: sometimes this is only after or just before an attack, sometimes during the preparatory stages, and sometimes before there are any plans for an attack at all.

Henk Rengelink's chapter provides some of the detailed description so lacking in the literature on organized crimes - in his case Somali piracy. His account of the way in which pirates take control of a merchant ship is a model of brevity and clarity and so is his explanation of the difficulties faced by naval vessels in policing pirates in their vast hunting grounds, as well as of the difficulties faced in prosecuting pirates who have been arrested. He explores the possibilities and limitations of the various interventions revealed by his analyses of modus operandi and opportunity structure before throwing his weight behind one highly innovative solution: the creation of "safe rooms" in which the captain and crew can hide themselves when their ship is about to be taken over by pirates. From these fortified rooms, the engines can be cut and distress signals can be sent to any nearby patrolling warship on which the effectiveness of the safe rooms depend.

His chapter is a model of how a situational analysis should be conducted if it is to inform preventive efforts. It also illustrates a truth shown repeatedly in the analysis of much simpler forms of crime: out of the many possible ways identified to reduce opportunities for that crime, it is often possible to find a single solution (sometimes supported by others) that can wipe out the crime entirely at an acceptable financial and social cost. Safe rooms appear to have that potential and Rengelink's analysis shows that they demand closer study.

Vijlbrief's chapter, "Looking for displacement effects: The case of ecstasy and amphetamine in the Netherlands," further illustrates the value of the disaggregation technique for analyzing crime organization as a diversified process. That analysis led directly to the prevention tactics. To impair illicit drug production, Dutch authorities hindered the availability of precursor chemicals, as well as other chemicals essential for the production process. They also hampered access to the glass vessels needed for the production of ecstasy and amphetamine. Analysis of clandestine laboratories had 
showed that criminal groups were using specially modified 20-liter round-bottom flasks. Such flasks were hardly ever used for legal purposes. These interferences may have reduced illegal production, but they also led to some adaptive technical changes by offenders, who continued production. This leads us to realize that not all stages of the crime process are equally amenable to disruption through situational prevention or focused policing. Although we have doubts about complicated and unfocused multi-point intervention plans, we also suggest that focusing requires further inquiry. We might learn that intervening at two key points in the crime process leads to effective reduction, but that is an empirical question. One should not assume that a 17-point plan is better than a one or two point plan. We are even willing to accept the possibility that one of our favorite strategies, controlling facilitators, might prove less effective than interfering with open sales to new customers. In order to study effectiveness one should seek considerable and detailed information about the modus operandi for each specific time of prolonged criminal cooperation.

Illegal tasks have logistical requirements. Offenders often cooperate in order to meet some of their logistical challenges, including a need to reach customers for illegal goods and services, as well as a need to find co-offenders. At least four mechanisms serve these logistical purposes: personal ties, shared activity space, internet and modern telecommunications, and legitimate occupational roles that provide access. We see all four of these mechanisms at play in the current articles. Some offenders find each other through personal ties, and others use common residence in trailer parks. Others use the internet or text messaging, while still others divert legitimate work roles to illegitimate purposes. Ongoing organization can provide a more efficient way for co-offenders to find each other and to find customers for illegal goods and services.

In conclusion, as we learn about preventing organized crime, we realize increasingly that the most central analytical chore is not always to find out which individuals are most powerful. Rather, the central task is to figure out what specific part of the activity is most subject to impairment, and how to make that work against the entire process.

\section{References}

Bouloukos AC, Farrell G, Laycock G (2003) Transnational organised crime in Europe and North America: The need for situational crime prevention efforts. HEUNI, Helsinki

Bullock K, Clarke RV, Tilley N (2010) Situational prevention of organised crimes. Willan Publishing, Cullompton

Cornish D, Clarke RV (2001) Analyzing organised crimes. In: Piquero AR, Tibbetts SG (eds) Rational choice and criminal behaviour: recent research and future challenges. Garland Science, Hamden

Felson M (2006) The ecosystem for organized crime, HEUNI Paper No. 26. HEUNI, Helsinki

Reuter P (1983) Disorganized crime: the economics of the visible hand. MIT Press, Cambridge

Van de Bunt H, Van der Schoot C (2003) Prevention of organised crime. WODC, The Hague

Van der Schoot C (2006) Organised crime prevention in the Netherlands. Ph.D. Thesis, Rotterdam: Erasmus University Rotterdam 